\title{
ANALYSIS OF COMPLICATED CERVICAL ECTOPY CLINICAL COURSE AND RECURRENCE
}

\author{
Yuliya Mazur \\ Department of Obstetrics, Gynecology, and Perinatology FPGE \\ Danylo Halytsky Lviv National Medical University \\ 69 Pekarska str., Lviv, Ukraine, 79010 \\ julia.mazur@ukr.net \\ Vira Pyrohova \\ Department of Obstetrics, Gynecology, and Perinatology FPGE \\ Danylo Halytsky Lviv National Medical University \\ 69 Pekarska str., Lviv, Ukraine, 79010
}

\begin{abstract}
Physiological cervical ectopy (CE) is commonly found in young women, during pregnancy or intake of oral contraceptives. The complicated (pathological) CE, particularly in conditions of vaginal microbiota disturbances and human papillomavirus (HPV) infection, requires intervention, including optimal treatment and effective relapse prevention approaches.

Aim. The aim of the research was to investigate the complicated CE clinical course and recurrence features on the basis of a retrospective analysis of archival medical records in order to optimize the tactics of the complicated CE management and the relapse prevention measures.

Materials and methods. In the observational cross-sectional retrospective study using the continuous sampling method were included 740 case reports of women, who underwent inpatient treatment of gynecological pathology in Lviv Municipal Clinical First Aid Hospital in 2006-2017. The inclusion criterion was the presence of firstly diagnosed or recurrent CE. Exclusion criteria: absence of CE colposcopic or morphological confirmation, presence of physiological CE (on conditions of cytological, bacterioscopical, bacteriological and colposcopical abnormalities absence). Subsequently, three groups were formed: control group ( $\mathrm{n}=150)$ - healthy women, who applied for a regular gynecological examination; group $1(n=483)$ - women with firstly diagnosed CE; group $2(n=257)-$ women with recurrent CE. Differences in mean values were considered significant with a probability level of at least $95 \%(\mathrm{p}<0.05)$.

Results. Patients with recurrent $\mathrm{CE}$ had more pregnancies $(\mathrm{p}<0.05)$ than the ones with firstly diagnosed CE and women of control group. The proportion of women with high parity in group 1 and group 2 was three times higher $(p<0.05)$, than in group 3. The proportion of artificial abortions in patients of groups 1 and 2 was more than two times higher $(p<0.05)$, than in women in the control group, group 2 patients had more miscarriages and missed miscarriages $(p<0.05)$ in comparison to the control group. Menarche in patients with recurrent CE set in later in comparison to women of control group $(\mathrm{p}<0.05)$. In group 2, the proportion of women with polymenorrhea was three times higher $(\mathrm{p}<0.05)$, than in group 1 and control group respectively. The compromised gynecological history was more often $(\mathrm{p}<0.05)$ detected in group 1 and group 2 , than in the control group. In patients with recurrent $\mathrm{CE}$ a third of gynecologic diseases in the history $(32.30 \pm 2.92 \%)$ and $23.60 \pm 1.93 \%$ - in patients with the firstly diagnosed CE were pelvic inflammatory diseases, significantly $(\mathrm{p}<0.05)$ higher in comparison to the control group $(3.33 \pm 1.47 \%)$. Almost half of patients in group $1(48.25 \pm 2.27 \%)$ and group $2(47.84 \pm 3.13 \%)$ had the history of frequent infectious diseases, this indicator was significantly $(p<0.05)$ higher in comparison to the control group $(24.67 \pm 3.52 \%)$. In patients with recurrent CE chronic diseases of different etiology were diagnosed more often $(\mathrm{p}<0.05)$ - their share made up $8.24 \pm 1.72 \%$, while in patients with firstly diagnosed CE $-4.33 \pm 0.92 \%$, in women of the control group $-1.33 \pm 0.94 \%$.The firstly diagnosed CE was more frequent (in comparison to recurrent $\mathrm{CE}$ ) ( $\mathrm{p}<0.001)$

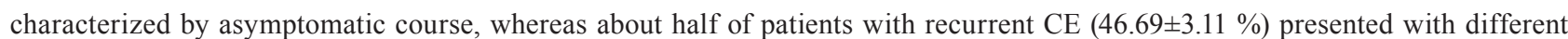
complaints. Cytological indicators of cervicitis were found more often in patients with firstly diagnosed and recurrent $\mathrm{CE}$, than in women of control group, as well as vaginal candidosis $(p<0.05)$. Patients with recurrent CE more often $(p<0.05)$ underwent diathermoconization $(24.12 \pm 2.67 \%)$ and cryodestruction of the cervix $(8.17 \pm 1.71 \%)$ in comparison to patients of group 1 . The most often performed treatment method in patients of both groups was diathermoconization. Treatment methods aimed to restore the hormonal balance, to normalize the state of vaginal microbiota were rarely found in both group 1 and 2, drugs that affect the reparation and regeneration of the epithelium have not been used in any case.

Conclusions. Recurrent symptomatic complicated CE should be interpreted as a complex problem that requires a multi-polar approach aimed at hormonal homeostasis, local immunity, and vaginal biocenosis normalizing. These measures should precede invasive treatment and further create optimal conditions for regeneration of the cervix.
\end{abstract}

Keywords: recurrent cervical ectopy, clinical course, treatment, prevention. 


\section{Introduction}

The presence of columnar epithelium on the vaginal portion of the cervix is known as cervical ectopy (CE), it is often diagnosed in young nulliparous women aged under 25 (in $52.2-$ $90 \%$ of cases) [1]. CE found in adolescents and women of a young age, during pregnancy, intake of estrogen-containing oral contraceptives [2] is considered to be physiological, does not require any treatment and is subject to dynamic monitoring.

Subsequently, in women with CE under the influence of reproductive hormones the physiological process of metaplasia is activated and, as a result, the generative cells of the columnar epithelium are transformed into squamous epithelium by remodeling process, which involves active replication and cell differentiation [3].

The complicated (pathological) CE, particularly in conditions of vaginal microbiota disturbances and human papillomavirus (HPV) infection, requires intervention, especially taking into account the significant relapse rate, which has no tendency to decrease and reaches $40 \%$ [4].

It has been established, that the presence of CE may increase the risk of sexually transmitted diseases (STDs) infection, in particular Chlamydia infection [5], Cytomegalovirus infection [6], HIV [7], and HPV [8].

Thus, the presence of active, long-term metaplastic changes creates favorable conditions for the HPV infection, its replication and persistence in the future [9, 10], which becomes especially relevant taking into account, that the HPV infection prevalence is the highest among women aged under 25-23.2\% [11]. In addition, in several cross-sectional studies, in particular among older women, a significant correlation between the presence of CE and the prevalence of HPV infection was found, in particular type 16 [12,13] and even more frequent - type 18 [14], presence of which is known to be associated with the cervical adenocarcinoma. A number of recent studies have also found that vaginal biocenosis disturbances play an important role in the development of cervical squamous intraepithelial lesions $[15,16]$.

However, despite the fact that $\mathrm{CE}$ has been intensively studied in recent years, there is still no unanimous hypothesis explaining its etiopathogenesis, tactics of the complicated CE optimal treatment (in particular, in conditions of vaginal microbiota disturbances and HPV infection) and effective technologies of relapse prevention, which substantiates the relevance of further study of this problem.

\section{Aim of research}

The aim of the study is to investigate the complicated CE clinical course and recurrence features on the basis of a retrospective analysis of archival medical records in order to optimize the tactics of the complicated CE management and relapse prevention measures.

\section{Materials and Methods}

In the observational cross-sectional retrospective study using the continuous sampling method were included 740 case reports of women, who underwent inpatient treatment of gynecological pathology in Lviv Municipal Clinical First Aid Hospital in 2006-2017. The inclusion criterion was the presence of firstly diagnosed or recurrent CE.

Exclusion criteria: absence of CE colposcopic or morphological confirmation, presence of physiological CE(on conditions of cytological, bacterioscopical, bacteriological and colposcopical abnormalities absence).

Subsequently, three groups were formed:

- control group $(\mathrm{n}=150)$ - healthy women, who applied for a regular gynecological examination;

- group $1(\mathrm{n}=483)$ - women with firstly diagnosed CE;

- group $2(\mathrm{n}=257)$ - women with recurrent CE.

The following data was taken into account: age, obstetrical and gynecological history, extragenital pathology, complaints, laboratory diagnostic data (bacterioscopical, bacteriological, cytological, molecular (PCR) data) and colposcopy results.

Statistical processing of the study results was conducted using the Student's t-criterion. Differences in mean values were considered significant with a probability level of at least $95 \%(\mathrm{p}<0.05)$. 


\section{Results}

Firstly diagnosed CE was found in $65.27 \pm 1.75 \%(n=483)$ of patients, recurrent CE - in $34.73 \pm 1.75 \%(n=257)$ of patients.

The average age of women in the control group was $26.55 \pm 0.64$ years, in group $1-33.55 \pm$ \pm 0.58 years, in group $2-34.64 \pm 0.57$ years. In all groups, the prevalence of women of early and active reproductive age (18-34 years) was found: in group 1 this cohort of patients amounted to $60.31 \pm 3.05 \%$, in the group $2-59.42 \pm 2.23 \%$, whereas in the control group this indicator reached the value of $84.67 \pm 2.94 \%$.

Every sixth patient with the firstly diagnosed CE $(15.32 \pm 1.64 \%)$ and recurrent $\mathrm{CE}$ $(15.56 \pm 2.26 \%)$ at least once underwent inpatient treatment because of the threatened miscarriage or premature labor. In every fifth patient $(21.74 \pm 1.88 \%$ and $22.96 \pm 2.62 \%$ respectively), the complicated course of at least one pregnancy was diagnosed. Cervical rupture during the labor was diagnosed in $7.87 \pm 1.23 \%$ of patients in group 1 and in $10.89 \pm 1.94 \%$ of group 2 patients.

Menarche in patients with recurrent CE set in significantly $(\mathrm{p}<0.05)$ later (on average in $13.59 \pm 0.05$ years) in comparison to women of control group.

The disorders of menstrual function were detected in more than half of women of all study groups (Table 1).

Table 1

Peculiarities of obstetrical and gynecological history of patients with CE in comparison to control group

\begin{tabular}{|c|c|c|c|}
\hline Indicator & $\begin{array}{l}\text { Group } 1 \\
(n=483)\end{array}$ & $\begin{array}{c}\text { Group } 2 \\
(n=257)\end{array}$ & $\begin{array}{c}\text { Control group } \\
(n=150)\end{array}$ \\
\hline Parity: & $1.80 \pm 0.06$ & $2.03 \pm 0.09 * * *$ & $1.16 \pm 0.09 * * *$ \\
\hline - labors: & $1.32 \pm 0.05$ & $1.46 \pm 0.06$ & $0.78 \pm 0.06^{* * *}$ \\
\hline $0, \%$ & $26.50 \pm 2.01$ & $17.51 \pm 2.37 * * *$ & $23.33 \pm 3.45$ \\
\hline $1, \%$ & $27.54 \pm 2.03$ & $29.96 \pm 2.86$ & $61.33 \pm 3.98 * * *$ \\
\hline 2 and more, $\%$ & $45.96 \pm 2.27$ & $52.53 \pm 3.11$ & $15.33 \pm 2.94 * * *$ \\
\hline - artificial abortions, $\%$ & $15.73 \pm 1.66$ & $14.79 \pm 2.21$ & $6.67 \pm 2.04 * * *$ \\
\hline - miscarriages, $\%$ & $10.14 \pm 1.37$ & $12.84 \pm 2.09$ & $6.67 \pm 2.04^{* *}$ \\
\hline - missed miscarriages, $\%$ & $2.72 \pm 1.02$ & $5.38 \pm 1.03$ & $0.67 \pm 0.66^{* *}$ \\
\hline Menarche, years: & $13.47 \pm 0.06$ & $13.59 \pm 0.05$ & $13.39 \pm 0.88^{* *}$ \\
\hline - early, \% & $0.83 \pm 0.41$ & $1.95 \pm 0.86$ & $1.33 \pm 0.94$ \\
\hline - late, $\%$ & $9.73 \pm 1.85$ & $10.56 \pm 1.40$ & $5.33 \pm 1.83 * *$ \\
\hline Menopause, $\%$ & $2.00 \pm 1.14$ & $8.49 \pm 1.27 * * *$ & $1.95 \pm 0.86^{* *}$ \\
\hline Menstrual function disturbances, $\%$ : & $64.39 \pm 2.18$ & $59.53 \pm 3.06$ & $58.00 \pm 4.03$ \\
\hline - hypermenorrhea, \% & $3.54 \pm 1.05$ & $10.46 \pm 2.47 * * *$ & - \\
\hline - oligomenorrhea, \% & $2.57 \pm 0.90$ & $3.27 \pm 1.44$ & $3.45 \pm 1.96$ \\
\hline - dysmenorrhea (painful menstruation), \% & $61.41 \pm 2.76$ & $57.52 \pm 4.00$ & $60.92 \pm 5.23$ \\
\hline - opsomenorrhea, \% & $3.22 \pm 1.00$ & $5.23 \pm 1.80$ & $5.75 \pm 2.50$ \\
\hline - proyomenorrhea, \% & $3.45 \pm 1.96$ & $9.80 \pm 2.40 * * *$ & $2.25 \pm 0.84 * *$ \\
\hline - irregular menstrual cycle, $\%$ & $26.44 \pm 4.73$ & $27.01 \pm 2.52$ & $15.33 \pm 2.94 * *$ \\
\hline
\end{tabular}

Note: $*_{-}-p<0.05$ between group 1 and control group; $* *_{-} p<0.05$ between group 2 and control group; $* * *-p<0.05$ between group 1 and group 2 
The compromised gynecological history was detected in more than a third of patients with the firstly diagnosed CE $(33.13 \pm 2.14 \%)$ and recurrent CE $(38.13 \pm 3.03 \%)$.

Analyzing the structure of gynecological diseases history presented in Table 2, it can be noted that the proportion of adenomyosis was significantly $(\mathrm{p}<0.05)$ higher in patients with firstly diagnosed $(9.32 \pm 1.32 \%)$ and recurrent $\mathrm{CE}(8.56 \pm 1.75 \%)$ in comparison to the control group $(2.00 \pm 1.14 \%)$. Patients of group 2 were more likely to have abnormal uterine bleeding (AUB) $(31.52 \pm 2.90 \%)$, Bartolin's cyst $(5.84 \pm 1.46 \%)$ in history in comparison to group 1 (13.46 \pm $\pm 1.55 \%$ and $0.41 \pm 0.29 \%$ respectively), while this pathology in women of the control group was not diagnosed. Also, proportion of ovarian cysts $(14.40 \pm 2.19 \%)$ and uterine fibroids $(20.62 \pm$ $\pm 2.52 \%$ ) was significantly $(\mathrm{p}<0.05)$ higher in patients with recurrent $\mathrm{CE}$ in comparison to group 1 and control group.

In patients with recurrent $\mathrm{CE}$ a third of gynecologic diseases in the history $(32.30 \pm 2.92 \%)$ and $23.60 \pm 1.93 \%$ - in patients with the firstly diagnosed CE were pelvic inflammatory diseases chronic salpingitis, oophoritis and endometritis, significantly $(\mathrm{p}<0.05)$ higher in comparison to the control group $(3.33 \pm 1.47 \%)$.

It should be noted, that $12.22 \pm 1.49 \%$ of patients in group 1 and $21.40 \pm 2.56 \%$ of patients in group 2 had the history of laparoscopic or laparotomy surgery on internal reproductive organs, which is significantly higher $(\mathrm{p}<0.05)$ compared to the control group, where this indicator was $6.00 \pm 1.94 \%$.

\section{Table 2}

The structure of gynecological diseases in the history of patients with CE and women of the control group

\begin{tabular}{|c|c|c|c|c|}
\hline No. & Disease & $\begin{array}{l}\text { Group } 1 \\
(n=483)\end{array}$ & $\begin{array}{l}\text { Group } 2 \\
(n=257)\end{array}$ & $\begin{array}{c}\text { Control group } \\
(n=150)\end{array}$ \\
\hline 1 & Adenomatosis, $\%$ & $1.04 \pm 0.46$ & $0.39 \pm 0.39$ & - \\
\hline 2 & Adenomyosis, $\%$ & $9.32 \pm 1.32$ & $8.56 \pm 1.75$ & $2.00 \pm 1.14 * * *$ \\
\hline 3 & AUB, \% & $13.46 \pm 1.55$ & $31.52 \pm 2.90^{* * *}$ & - \\
\hline 4 & Bartolin's cyst, \% & $0.41 \pm 0.29$ & $5.84 \pm 1.46^{* * *}$ & \\
\hline 5 & Cervical polyp, $\%$ & $4.76 \pm 0.97$ & $7.00 \pm 1.59$ & - \\
\hline 6 & Chronic endometritis, $\%$ & $3.93 \pm 0.88$ & $5.84 \pm 1.46$ & - \\
\hline 7 & Chronic salpingitis, oophorotis, \% & $19.67 \pm 1.81$ & $26.46 \pm 2.75^{* * *}$ & $3.33 \pm 1.47 * * *$ \\
\hline 8 & CIN I, \% & $12.42 \pm 1.50$ & $11.28 \pm 1.97$ & - \\
\hline 9 & CIN II, \% & $1.86 \pm 0.62$ & $5.84 \pm 1.46$ & - \\
\hline 10 & CIN III, \% & $0.62 \pm 0.36$ & $0.78 \pm 0.55$ & - \\
\hline 11 & Ectopic pregnancy, $\%$ & $2.90 \pm 0.76$ & $1.56 \pm 0.77$ & - \\
\hline 12 & Endometrial hyperplasia, \% & $14.29 \pm 1.59$ & $12.45 \pm 2.06$ & - \\
\hline 13 & Endometriosis, \% & $2.90 \pm 0.76$ & $1.56 \pm 0.77$ & - \\
\hline 14 & Ovarian apoplexy, \% & $3.73 \pm 0.86$ & $1.95 \pm 3.33$ & $3.33 \pm 1.47$ \\
\hline 15 & Ovarian cyst, \% & $9.11 \pm 1.31$ & $14.40 \pm 2.19 * * *$ & $6.00 \pm 1.94 * *$ \\
\hline 16 & PCOS, $\%$ & $2.28 \pm 0.68$ & $0.78 \pm 0.55$ & $1.33 \pm 0.94$ \\
\hline 17 & Pelvic organ prolapse, $\%$ & - & $8.17 \pm 1.71$ & - \\
\hline 18 & Primary sterility, $\%$ & $1.24 \pm 0.50$ & $1.17 \pm 0.67$ & $4.00 \pm 1.60$ \\
\hline 19 & Secondary sterility, \% & $0.62 \pm 0.36$ & - & - \\
\hline 20 & Uterine fibroids, $\%$ & $11.39 \pm 1.45$ & $20.62 \pm 2.52 * * *$ & $3.33 \pm 1.47 * * *$ \\
\hline
\end{tabular}

Note: ${ }^{*}-p<0.05$ between group 1 and control group; $*^{*}-p<0.05$ between group 2 and control group; $* * *-p<0.05$ between group 1 and group 2 
It was noted, that $48.25 \pm 2.27 \%$ of patients in group 1 and $47.84 \pm 3.13 \%$ - in group 2 had in the history frequent infectious diseases, this indicator was significantly $(p<0.05)$ higher in comparison to the control group (24.67 $\pm 3.52 \%$ ). In patients with recurrent $C E$ the share of chronic diseases of different etiology made up $8.24 \pm 1.72 \%$, while in patients with firstly diagnosed CE $-4.33 \pm$ $\pm 0.92 \%$, in women of the control group $-1.33 \pm 0.94 \%$. The compromised allergic history was detected in $7.00 \pm 1.59 \%$ of the patients in group 2 , this indicator was significantly $(\mathrm{p}<0.05)$ higher, than the one in the control group $(2.67 \pm 1.32 \%)$. Among other diseases, the proportion of anemia should be noted, this indicator in group $1(42.06 \pm 2.24 \%)$ and group $2(41.96 \pm 3.09 \%)$ was almost two times higher $(\mathrm{p}<0.05)$ in comparison to the control group $(25.33 \pm 3.55 \%)$.

Firstly diagnosed CE was more frequently (in comparison to recurrent $\mathrm{CE})(\mathrm{p}<0.001)$ characterized by asymptomatic course, whereas about half of patients with recurrent CE (46.69土 $\pm 3.11 \%)$ presented with different complaints, the most common $(\mathrm{p}<0.05)-$ of the blood mixed discharge presence (compared with patients of group 1). Also, more often $(p<0.001)$, than patients in group 1 , this category of patients was disturbed by poscoital bleeding $(5.45 \pm 1.42 \%)$.

It is characteristic, that the interval from the moment of complicated symptomatic $\mathrm{CE}$ diagnosis to obtaining appropriate treatment in patients with recurrent CE was significantly $(p<0.001)$ longer (compared to patients of group 1) and averaged $4.05 \pm 0.49$ years. At the same time, it was noted, that in patients of group 2 carriage of high-risk HPV was diagnosed more often $(\mathrm{p}<0.05)$.

The colposcopy results in the two groups of patients were not significantly different, however, in patients of group 2, the presence of non-uniform iodine uptake zones was significantly $(\mathrm{p}<0.05)$ higher (Table 3$)$.

Table 3

Features of the firstly diagnosed and recurrent CE clinical course

\begin{tabular}{|c|c|c|}
\hline Indicator & Group $1(n=483)$ & Group $2(n=257)$ \\
\hline Complaints, \%: & $28.57 \pm 2.06$ & $46.69 \pm 3.11 * *$ \\
\hline - lower abdominal pain, $\%$ & $6.21 \pm 1.10$ & $9.34 \pm 1.82$ \\
\hline - blood mixed discharge, $\%$ & $19.67 \pm 1.81$ & $36.58 \pm 3.00 * *$ \\
\hline - postcoital bleeding, $\%$ & $2.07 \pm 0.65$ & $5.45 \pm 1.42 *$ \\
\hline - foul smelling vaginal discharge, vaginal itching, $\%$ & $7.45 \pm 1.20$ & $8.95 \pm 1.78$ \\
\hline Duration of CE presence, years & $1.06 \pm 0.12$ & $4.05 \pm 0.49 * *$ \\
\hline High-risk HPV carriage, \% & $4.97 \pm 0.99$ & $10.89 \pm 1.94 *$ \\
\hline CE diameter, $\mathrm{cm}$ & $2.02 \pm 0.08$ & $2.55 \pm 0.12 * *$ \\
\hline \multicolumn{3}{|l|}{ Colposcopic findings: } \\
\hline - acetic-white epithelium, $\%$ & $12.28 \pm 4.35$ & $18.33 \pm 5.00$ \\
\hline - atypical TZ, \% & - & $1.67 \pm 1.65$ \\
\hline - cervical hypertrophy, $\%$ & $12.28 \pm 4.35$ & $3.33 \pm 2.32$ \\
\hline - dilatation of the superficial vessels, $\%$ & $12.28 \pm 4.35$ & $10.00 \pm 3.87$ \\
\hline - excretory ducts of glands, $\%$ & $7.02 \pm 3.38$ & $1.67 \pm 1.65$ \\
\hline - mosaic, $\%$ & $10.53 \pm 4.06$ & $13.33 \pm 4.39$ \\
\hline - non-uniform iodine uptake zone, $\%$ & $3.51 \pm 2.44$ & $15.00 \pm 4.61^{*}$ \\
\hline - Nabothian cyst, $\%$ & $14.04 \pm 4.60$ & $6.67 \pm 3.22$ \\
\hline - punctuation, $\%$ & $8.77 \pm 3.75$ & $11.67 \pm 4.14$ \\
\hline - TZ type $1, \%$ & $14.04 \pm 4.60$ & $18.33 \pm 5.00$ \\
\hline
\end{tabular}

Note: $*_{-}-p<0.05$ between group 1 and control group; $*^{*}-p<0.05$ between group 2 and control group 
The highest percentage of cytological norm was found in women of the control group $60.00 \pm 4.00 \%$ (Pap smear) and $93.33 \pm 2.04 \%$ respectively (Bethesda, 2001), which is significantly $(\mathrm{p}<0.05)$ higher, than in patients of group 1 and 2 . Identical trends were also observed in the case of type IIA and IIB (Pap smear) and ASC-US (Bethesda, 2001).

The level of leukocytes found during bacterioscopy was significantly $(\mathrm{p}<0.05)$ higher in patients of group $1(35.04 \pm 1.73 \%)$ and group $2(37.75 \pm 1.38 \%)$ in comparison to the control group $(13.99 \pm 1.21 \%)$ (Table 4).

Table 4

Features of cytology, bacterioscopy and bacteriology in patients with CE and women of control group

\begin{tabular}{|c|c|c|c|}
\hline Indicator & Group $1(n=483)$ & Group $2(n=257)$ & Control group $(n=150)$ \\
\hline \multicolumn{4}{|l|}{ Cytology: } \\
\hline \multicolumn{4}{|l|}{ - Pap smear } \\
\hline type I, \% & $19.05 \pm 1.79$ & $16.34 \pm 2.31$ & $60.00 \pm 4.00 * * *$ \\
\hline type IIA, \% & $47.41 \pm 2.27$ & $48.64 \pm 3.12$ & $33.33 \pm 3.85^{*} * *$ \\
\hline type IIB, \% & $20.08 \pm 1.82$ & $23.35 \pm 2.64$ & $6.67 \pm 2.04 * * *$ \\
\hline type IIIA, \% & $11.80 \pm 1.47$ & $10.12 \pm 1.88$ & - \\
\hline type IIIB, \% & $1.66 \pm 0.58$ & $1.56 \pm 0.77$ & - \\
\hline \multicolumn{4}{|l|}{ - Bethesda (2001) } \\
\hline NILM, \% & $66.46 \pm 2.15$ & $64.98 \pm 2.98$ & $93.33 \pm 2.04 * * *$ \\
\hline ASC-US, \% & $20.08 \pm 1.82$ & $23.35 \pm 2.64$ & $6.67 \pm 2.04 * * *$ \\
\hline LSIL, \% & $11.80 \pm 1.47$ & $10.12 \pm 1.88$ & - \\
\hline HSIL, \% & $1.66 \pm 0.58$ & $1.56 \pm 0.77$ & - \\
\hline \multicolumn{4}{|l|}{ Bacterioscopy: } \\
\hline \multicolumn{4}{|l|}{ - flora } \\
\hline bacilli, $\%$ & $67.70 \pm 2.13$ & $66.15 \pm 2.95$ & $71.33 \pm 3.69$ \\
\hline cocci, $\%$ & $8.70 \pm 1.28$ & $8.56 \pm 1.75$ & $4.67 \pm 1.72$ \\
\hline mixed, $\%$ & $23.60 \pm 1.93$ & $25.29 \pm 2.71$ & $24.00 \pm 3.49$ \\
\hline - leucocytes & $35.04 \pm 1.73$ & $37.75 \pm 1.38$ & $13.99 \pm 1.21 * * *$ \\
\hline \multicolumn{4}{|l|}{ Bacteriology: } \\
\hline -C. albicans, \% & $19.07 \pm 2.45$ & $26.29 \pm 2.00$ & $13.33 \pm 2.78^{*} * *$ \\
\hline - G. vaginalis, $\%$ & $8.00 \pm 2.22$ & $7.00 \pm 1.59$ & $5.80 \pm 1.06$ \\
\hline - Tr. vaginalis, $\%$ & $2.33 \pm 0.94$ & $3.31 \pm 0.81$ & $0.67 \pm 0.66^{* *}$ \\
\hline - pseudomycosis, $\%$ & $2.72 \pm 1.02$ & $4.55 \pm 0.95$ & $2.67 \pm 1.32$ \\
\hline
\end{tabular}

Note: ${ }^{*}-p<0.05$ between group 1 and control group; $* *-p<0.05$ between group 2 and control group

Conservative treatment was taken by patients with firstly diagnosed CE significantly $(\mathrm{p}<0.001)$ more rarely $(26.29 \pm 2.00 \%$ of cases $)$ and mainly included local NSAIDs $(28.57 \pm$ $\pm 2.06 \%)$ and wide spectrum antibiotic therapy $(20.29 \pm 1.83 \%)$. Only in $11.39 \pm 1.45 \%$ of cases vaginal antiseptics were used, in $3.93 \pm 0.88 \%$ of cases- treatment aimed to restore the hormonal balance, in $1.86 \pm 0.62 \%$ of cases - drugs that normalize the state of vaginal microbiota. Drugs that affect the reparation and regeneration of the epithelium have not been prescribed in any case. A similar trend was observed in patients with recurrent CE. 
While analyzing the structure of surgical treatment methods, it was noted, that patients with recurrent CE significantly $(\mathrm{p}<0.05)$ more often underwent diathermoconization $(24.12 \pm 2.67 \%)$ and cryodestruction of the cervix $(8.17 \pm 1.71 \%)$ in comparison to patients of group 1 . The treatment method most often performed in patients of both groups was particular diathermoconization (Fig. 1).

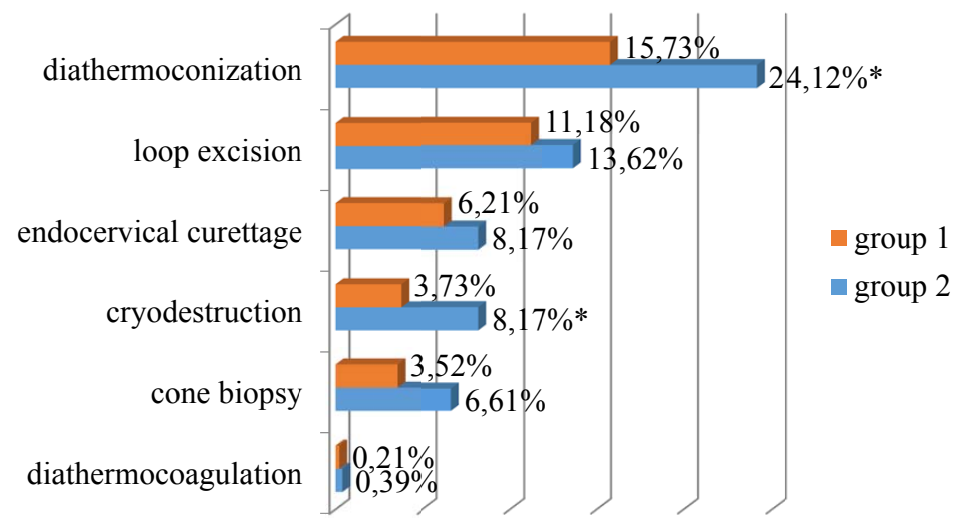

Fig. 1. The structure of CEsurgical treatment methods $(*-p<0.05$ between group 1 and group 2)

It should be noted, that $5.80 \pm 1.06 \%$ of group 1 patients and $6.23 \pm 1.51 \%$ of group 2 patients, who underwent either loop excision, or diathermoconization at the time of the intervention were nulliparous.

\section{Discussion}

In recent years the medical community attitude to the $\mathrm{CE}$ has shifted its vector: with the introduction of colposcopy and the implementation of the Bethesda system (2001) principles [17] in the routine medical practice, $\mathrm{CE}$ is now commonly interpreted as a physiological state, which does not require any intervention.

However, there is a problem unsolved concerning patients category, in which the presence of $\mathrm{CE}$ is associated with definite clinical symptoms, which create discomfort and may affect the quality of life, as well as the pathological CE, when the epithelization is complicated or impeded due to the presence of hormonal, local immunity, vaginal biocenosis disorders, HPV infection and chronic vaginal or cervical inflammatory processes.

We studied the clinical course and recurrence features of both firstly diagnosed and recurrent $\mathrm{CE}$, which should be taken into account when choosing thecomplicated CEoptimal treatment tactics, also aiming to prevent its relapse in the future.

Analyzing the obstetrical and gynecological history (Table 1), it was found that patients with recurrent $C E$ had significantly $(\mathrm{p}<0.05)$ more pregnancies, than the ones with firstly diagnosed CE and healthy women. A similar connection was noted in other studies [18]. The proportion of women with high parity ( 2 and more labors per vias naturalis) in group 1 and group 2 was three times higher $(\mathrm{p}<0.05)$, than in group 3 , which can be explained by the probable relationship between obstetric trauma and CE in this contingent of patients [19].

The proportion of artificial abortions in the history of patients in groups 1 and 2 was more than two times higher $(\mathrm{p}<0.05)$, than in women of the control group. In addition, group 2 patients had significantly more $(\mathrm{p}<0.05)$ miscarriages and missed miscarriages in comparison to the control group.

It was also found that hypermenorrhea was significantly $(\mathrm{p}<0.05)$ more commonly diagnosed in patients of group 2 in comparison to group 1, this disturbance was not found among women of control group. In group 2, the proportion of women with polymenorrhea was three times higher $(\mathrm{p}<0.05)$, than in group 1 and control group respectively.

Compromised gynecological history (especially concerning the pathology related with hormonal disturbances and chronic pelvic inflammatory diseases) was more typical for patients with CE: this indicator was significantly $(\mathrm{p}<0.05)$ higher in group 1 and group 2 , than in the control group. 
Almost half of patients in group 1 and group 2 had in the history frequent (more than 3 times a year) infectious diseases (ARI, influenza, pneumonia), this indicator was significantly $(\mathrm{p}<0.05)$ higher in comparison to the control group. In patients with recurrent CE chronic diseases of different etiology (in particular, chronic bronchitis, tonsillitis, pyelonephritis) were diagnosed more often $(\mathrm{p}<0.05)$, than in group 1 and control group.

The size of the CE, measured during colposcopy, in patients of group 2, compared to patients of group 1, was significantly $(\mathrm{p}<0.001)$ greater. It was found, that in the presence of CE with a diameter greater than $3.5 \mathrm{~mm}$, the risk of postcoital bleeding increases [20], which explains the higher prevalence of this symptom in patients with recurrent CE.

The frequent presence of cervicitis cytological indicators in patients with firstly diagnosed and recurrent CE correlates with the results of other studies: Singh et al. [21], studying the etiology of inflammatory cervical smears, found CE in a significant proportion of patients; moreover, the presence of CE can be associated with recurrent cervicitis [19].

This fact should be taken into account when choosing the treatment method for complicated $\mathrm{CE}$, as it has been established that, in particular, cryodestruction of $\mathrm{CE}$ in patients with $\geq 3$ episodes of cervicitis exacerbation during the past 6 months was 9 times less effective [19].

Vaginal candidiasis was diagnosed more often $(p<0.05)$ in patients with firstly diagnosed and recurrent CE in comparison with control group (Table 4). A similar feature of vaginal microbiota was discovered by other researchers [22], who suggest that the dominance of C. albicans is a favorable factor for CE existence [23].

As our study showed, in practice, surgical treatment methods of complicated CE are still commonly used, unlike the treatment aimed at normalizing hormonal balance, vaginal microbiota, and promoting the processes of cervical epithelium regeneration. The shifting of the emphasis from the causes of CE and its long-term existence to the elimination of the consequences - the CE itself, is probably also one of the recurrence causes.

\section{Conclusions}

1. Complicated recurrent $\mathrm{CE}$ should not be treated as an isolated pathology, that can be eliminated radically and quickly using only local means (both drugs and surgery), but as a possible indicator of reproductive health in women and should not be neglected.

2. The risk factors of recurrent CE include: 2 or more labors per vias naturalis, abortions, artificial abortions, miscarriages and missed miscarriages in the history, late menarche, menstrual function disorders such as polymenorrhea, compromised gynecological history (the diseasesprovoked by hormonal homeostasis disorders: adenomyosis, ovarian cysts, uterine fibroids, as well as chronic pelvic inflammatory diseases), the presence of extragenital pathology (frequent infectious diseases, chronic diseases, compromised alergological history, anemia).

3. Recurrent $\mathrm{CE}$ is characterized by symptomatic clinical course, it is more often combined with the HPV carriage, colpitis and cervicitis (often of mixed etiology), disturbances of vaginal microbiota, but at the same time, patients tend to postpone treatment for a long time.

4. Among the used first-line treatment methods of firstly diagnosed as well as recurrent CE, the lion's share takes surgical treatment in combination with the common use of wide spectrum antibacterial therapy and non-steroidal anti-inflammatory drugs.

5. Thus, recurrent symptomatic complicated CE should be interpreted as a complex problem that requires a multi-polar approach aimed at hormonal homeostasis, local immunity, and vaginal biocenosis normalizing. These measures should precede invasive treatment and further create optimal conditions for the cervix regeneration.

\section{References}

[1] Baseman, J. G., Koutsky, L. A. (2005). The epidemiology of human papillomavirus infections. Journal of Clinical Virology, 32, 16-24. doi: 10.1016/j.jcv.2004.12.008

[2] Lee, V., Tobin, J. M., Foley, E. (2006). Relationship of cervical ectopy to chlamydia infection in young women. Journal of Family Planning and Reproductive Health Care, 32 (2), 104-106. doi: $10.1783 / 147118906776276440$ 
[3] Hwang, L. Y., Ma, Y., Shiboski, S. C., Farhat, S., Jonte, J., Moscicki, A.-B. (2012). Active Squamous Metaplasia of the Cervical Epithelium Is Associated With Subsequent Acquisition of Human Papillomavirus 16 Infection Among Healthy Young Women. Journal of Infectious Diseases, 206 (4), 504-511. doi: $10.1093 /$ infdis/jis398

[4] Govsejev, D. A., Skorbach, E. I., Dynnik, A. A. (2014). The effectiveness of current diagnostic approaches to the problem of nonmalignant pathology of the cervix in women of reproductive age. Medicine today and tomorrow, 2/3, 128-133.

[5] Critchlow, C. W., Wlner-Hanssen, P., Eschenbach, D. A., Kiviat, N. B., Koutsky, L. A., Stevens, C. E., Holmes, K. K. (1995). Determinants of cervical ectopia and of cervicitis: Age, oral contraception, specific cervical infection, smoking, and douching. American Journal of Obstetrics and Gynecology, 173 (2), 534-543. doi: 10.1016/0002-9378(95)90279-1

[6] Collier, A. C., Handsfield, H. H., Ashley, R., Roberts, P. L., DeRouen, T., Meyers, J. D., Corey, L. (1995). Cervical But Not Urinary Excretion Of Cytomegalovirus Is Related To Sexual Activity And Contraceptive Practices In Sexually Active Women. Journal of Infectious Diseases, 171 (1), 33-38. doi: 10.1093/ infdis/171.1.33

[7] Plourde, P. J., Pepin, J., Agoki, E., Ronald, A. R., Ombette, J., Tyndall, M. et. al. (1994). Human Immunodeficiency Virus Type 1 Seroconversion in Women with Genital Ulcers. Journal of Infectious Diseases, 170 (2), 313-317. doi: 10.1093/infdis/170.2.313

[8] Venkatesh, K. K., Cu-Uvin, S. (2012). Assessing the Relationship Between Cervical Ectopy and HIV Susceptibility: Implications for HIV Prevention in Women. American Journal of Reproductive Immunology, 69, 68-73. doi: 10.1111/aji.12029

[9] Von Knebel Doeberitz, M. (2002). New markers for cervical dysplasia to visualise the genomic chaos created by aberrant oncogenic papillomavirus infections. European Journal of Cancer, 38 (17), 2229 2242. doi: 10.1016/s0959-8049(02)00462-8

[10] Doorbar, J. (2006). Molecular biology of human papillomavirus infection and cervical cancer. Clinical Science, 110 (5), 525-541. doi: 10.1042/cs20050369

[11] Bruni, L., Diaz, M., Castellsague, X., Ferrer, E., Bosch, F. X., de Sanjose, S. (2010). Cervical Human Papillomavirus Prevalence in 5 Continents: Meta-Analysis of 1 Million Women with Normal Cytological Findings. The Journal of Infectious Diseases, 202 (12), 1789-1799. doi: 10.1086/657321

[12] Castle, P. E., Jeronimo, J., Schiffman, M., Herrero, R., Rodriguez, A. C., Bratti, M. C. et. al. (2006). Age-Related Changes of the Cervix Influence Human Papillomavirus Type Distribution. Cancer Research, 66 (2), 1218-1224. doi: 10.1158/0008-5472.can-05-3066

[13] Rocha-Zavaleta, L., Yescas, G., Cruz, R. M., Cruz-Talonia, F. (2003). Human papillomavirus infection and cervical ectopy. International Journal of Gynecology \& Obstetrics, 85 (3), 259-266. doi: 10.1016/ j.ijgo.2003.10.002

[14] Monroy, O. L., Aguilar, C., Lizano, M., Cruz-Talonia, F., Cruz, R. M., Rocha-Zavaleta, L. (2010). Prevalence of human papillomavirus genotypes, and mucosal IgA anti-viral responses in women with cervical ectopy. Journal of Clinical Virology, 47 (1), 43-48. doi: 10.1016/j.jcv.2009.10.008

[15] Audirac-Chalifour, A., Torres-Poveda, K., Bahena-Roman, M., Tellez-Sosa, J., Martinez-Barnetche, J., Cortina-Ceballos, B. et. al. (2016). Cervical Microbiome and Cytokine Profile at Various Stages of Cervical Cancer: A Pilot Study. PLOS ONE, 11 (4), e0153274. doi: 10.1371/journal.pone.0153274

[16] Mitra, A., MacIntyre, D. A., Lee, Y. S., Smith, A., Marchesi, J. R., Lehne, B. et. al. (2015). Cervical intraepithelial neoplasia disease progression is associated with increased vaginal microbiome diversity. Scientific Reports, 5 (1). doi: 10.1038/srep16865

[17] Nayar, R., Wilbur, D. C. et. al. (2015). The Bethesda System for Reporting Cervical Cytology. Definitions, Criteria, and Explanatory Notes. Cham: Springer, 342. doi: 10.1007/978-3-319-11074-5

[18] Kleppa, E., Holmen, S. D., Lillebo, K., Kjetland, E. F., Gundersen, S. G., Taylor, M. et. al. (2014). Cervical ectopy: associations with sexually transmitted infections and HIV. A cross-sectional study of high school students in rural South Africa. Sexually Transmitted Infections, 91 (2), 124-129. doi: 10.1136/ sextrans-2014-051674

[19] Cekmez, Y., Sanlikan, F., Gocmen, A., Vural, A., Turkmen, S. B. (2015). Is Cryotherapy Friend or Foe for Symptomatic Cervical Ectopy? Medical Principles and Practice, 25 (1), 8-11. doi: 10.1159/ 000441433 
[20] Narin, R., Narin, M. A., Nazik, H. et. al. (2015). The importance of size of cervical ectopy to predict postcoital bleeding: is there any cut-off value? Clinical and Experimental Obstetrics and Gynecology, $42(2), 195-198$.

[21] Singh, V., Parashari, A., Satyanarayana, L., Sodhani, P., Gupta, M. M., Sehgal, A. (1999). Biological behavior and etiology of inflammatory cervical smears. Diagnostic Cytopathology, 20 (4), 199-202. doi: 10.1002/(sici)1097-0339(199904)20:4<199::aid-dc3>3.0.co;2-2

[22] Sanchez, A., Rivera, A., Castillo, F., Ortiz, S. (2012). Cervical erosion as result of infectious vaginitis. European Journal of Experimental Biology, 2 (5), 1659-1663.

[23] Trejo, J., Hernandez, B., Carrasco, J. et. al. (2003). Guia clinica para el diagnostico, tratamiento y prevencion de cervicovaginitis por bacterias, Trichomonas y Candida. Revista Medica del Instituto Mexicano del Seguro Social, 41, 71-76.

\title{
PROGNOSTIC VALUE OF IMMUNOHISTOCHEMICAL MARKERS IN PATIENTS WITH DIFFUSE LARGE B-CELL LYMPHOMA
}

\author{
Arina Martynchyk \\ Scientific Research Department of Chemotherapy of Hemoblastoses and Adjuvant Treatment Methods \\ National Cancer Institute \\ 33/43 Lomonosova str., Kyiv, Ukraine, 03022 \\ martynchyk.arina@gmail.com \\ Vitaliy Gurianov \\ Department of Medical Physics \\ Bogomolets National Medical University \\ 13 Shevchencko ave., Kyiv, Ukraine, 01601 \\ i_@ukr.net \\ Iryna Kriachok \\ Scientific Research Department of Chemotherapy of Hemoblastoses and Adjuvant Treatment Methods \\ National Cancer Institute \\ 33/43 Lomonosova str., Kyiv, Ukraine, 03022 \\ irina.kryachok@unci.org.ua
}

\begin{abstract}
Diffuse large B-cell lymphoma (DLBCL) is a potentially curable disease, but standard treatment is not effective enough for all patients. That is why so important to identify high risk patients who need more aggressive therapy at the time of diagnosis. Nowadays prognosis for patients with DLBCL is based on International prognostic index (IPI). However, this index consists of only clinical parameters and does not include the biological characteristics of the tumour. Immunohistochemistry (IHC) markers could also play a prognostic role. There are some publications regarding predictive and prognostic role of expression of Bcl-2, Bcl-6, MUM1, $\mathrm{CD} 10$ and CD30, but their results are controversial. The aim of our study was to analyze prognostic role of these markers, to compare survival of patients with positive and negative expression of these markers and to build a prognostic model which include biological parameters for identifying high risk patients. There were statistically significant differences in EFS between the group of patients with negative and positive expression of CD10 (51.5\% versus $72.5 \%, \mathrm{p}=0.01)$ and in OS between the group of patients with negative and positive expression of Bcl-6 (61.1\% versus 79.6\%, $\mathrm{p}=0.03)$. Six-factors nonlinear neural network prediction model (MLP_6) was built. The sensitivity of the model is $63.2 \%$ (95 \% CI $49.3 \%-75.6 \%)$, specificity $-85.2 \%$ (95\% CI $79.1 \%-90.1 \%)$. Prognostic factors include negative IHC expression of Bcl-6, CD10, non-GCB molecular subtype (according to algorithm Hans), gender (male), advanced Ann-Arbor stages, $>2$ extranodal involvement. Our nonlinear neural network prediction model could improve prognostic role of IPI by adding of biological tumour characteristics (IHC expression of CD10, Bcl-6, molecular subtype by IHC algorithm).

Keywords: diffuse large B-cell lymphoma, prognosis, predictive model, biological characteristics.
\end{abstract}

